\title{
Influence of crystallization conditions and of gaseous ammonia treatment on mesoporous $\mathrm{TiO}_{2}$ properties
}

\author{
Issam Naboulsi ${ }^{\mathrm{a}}$, Bénédicte Lebeau ${ }^{\mathrm{b}}$, Laure Michelin ${ }^{\mathrm{b}},{\text { Cédric } \text { Carteret }^{\mathrm{c}} \text {, Magali Bonne }}^{\mathrm{b}}$, and
} Jean-Luc Blin ${ }^{\mathrm{a} *}$

a: Université de Lorraine/CNRS, SRSMC, UMR7565, F-54506 Vandoeuvre-lès-Nancy cedex, France

${ }^{\mathrm{b}}$ : Université de Haute Alsace (UHA)/CNRS, Axe Matériaux à Porosité Contrôlée (MPC), Institut de Science des Matériaux de Mulhouse (IS2M), UMR 7361, F-68093 Mulhouse cedex, France

${ }^{c}$ : Université de Lorraine/CNRS, LCPME, UMR7564, F-54600 Villers-lès-Nancy, France

* Corresponding authors :

Pr. Jean-Luc Blin

Université de Lorraine

SRSMC UMR 7565

Faculté des Sciences et Technologies

BP 70239

F-54506 Vandoeuvre-lès-Nancy cedex, France

Tel. +33 383684370

E-mail: Jean-Luc.Blin@univ-lorraine.fr

Dr. Bénédicte Lebeau

Université de Haute Alsace (UHA), CNRS, Axe Matériaux à Porosité Contrôlée (MPC), Institut de Science des Matériaux de Mulhouse (IS2M), UMR 7361, ENSCMu

3 bis rue Alfred Werner

F-68093 Mulhouse cedex, France

Tel. +33 389336882

E-mail: Benedicte.Lebeau@uha.fr 


\section{Abstract}

After surfactant removal by ethanol extraction, amorphous mesoporous titania, synthesized through a soft templating method have been crystallized under different atmosphere: synthetic air, nitrogen followed by exposition to oxygen flow and pure nitrogen at 300,350 or $380^{\circ} \mathrm{C}$. The photocatalysis efficiency towards methyl orange degradation of the materials crystallized under oxidizing conditions increases with the calcination temperature thanks to the enhancement of crystallinity and the growth of anatase particles. However, if samples are heated under nitrogen followed by exposition to oxygen flow the mesopores collapse during the transformation of the amorphous titania walls at $380^{\circ} \mathrm{C}$. By contrast, under pure nitrogen atmosphere the photodegradation of the dye is not governed by the anatase particles but it is related to the specific surface area of the photocatalyst. A good compromise between avoiding the collapse of the mesostucture and improving photocatalytic efficiency consists in crystallizing the amorphous $\mathrm{TiO}_{2}$ under synthetic air at $380^{\circ} \mathrm{C}$.

In the synthesis procedure, to avoid the mesostucture collapse upon surfactant removal, a treatment of the hybrid mesophase under ammonia atmosphere is needed to complete the condensation of the titania precursor. Because of the possible interactions between ammonia and amorphous titania but also with surfactant, a wormhole-like structure is obtained, when the hybrid mesophase is exposed either at high $\mathrm{NH}_{3}$ pressure or for a long time. Conditions under which this step is performed also strongly affect the photocatalytic efficiency of the crystallized $\mathrm{TiO}_{2}$. Our results show that when the ammonia pressure is increased or when the treatment is prolonged, interaction of $\mathrm{NH}_{3}$ with amorphous titania through Lewis adsorption promotes the nucleation of rutile. Therefore, upon calcination less amorphous $\mathrm{TiO}_{2}$ particles can be transformed into nanosized anatase. Consequently, a decay of the photocatalytic efficiency is noted.

Keywords : Mesoporous titania, Soft templating, Crystallization, Ammonia treatment 


\section{Introduction}

Titania has potential interest in various fields such as electronic, photocatalysis, adsorption, sensors, as catalyst or as promoter or carrier for metals and their complexes [1-6]. For example, titanium dioxide represents a good photocatalyst for wastewater treatment, air purification or self-cleaning surfaces [7,8]. When used in catalysis, it enhances the hydrodesulfurization (HDS) of transition metal sulfides (TMS) by transferring electronic density towards the TMS [9]. More recently, thanks to their good biocompatibility titaniabased materials have attracted much attention for enzyme immobilization. For example, Gao et al. have reported the immobilization of horseradich peroxidase (HRP) in templated titania through the biomimetic titanification process [10]. The authors have shown that the encapsulated HRP exhibits improvement of $\mathrm{pH}$ and thermal stability as well as tolerance against inactive agents. The encapsulated HRP also presents better removal efficiency than the free enzyme for the removal of both phenol and 2-chlorophenol. The specific surface area and the pore size are key parameters for all these applications; thus, many efforts have been devoted to the design of porous titania. Usually these materials are synthesized from the solgel process using titanium alkoxides as precursors. Using this technique, Tan et al. have obtained macro-mesoporous $\mathrm{TiO}_{2}$ monoliths, adopting anatase structure, by hydrolysis and condensation of titanium isopropoxide under acidic conditions. The bimodal titania have been successfully used for the chromatic separation of carboxylate compounds [11]. Starting from the same precursor, but performing a hydrothermal treatment at different temperatures from 40 to $240^{\circ} \mathrm{C}$, Koodali et al. have synthesized efficient photocatalysts for the degradation of rhodamine B under visible light irradiation [12]. Using the sol-gel approach the textural properties of the $\mathrm{TiO}_{2}$ materials are mainly controlled by the synthesis conditions such as the

$\mathrm{pH}$, the gel composition, the humidity and so on. The textural properties of the porous $\mathrm{TiO}_{2}$ can also be enhanced by combining the sol-gel process with the surfactant templating 
mechanism [13-17], reported for the preparation of the ordered mesoporous silica materials. Comparing with the hard templating mechanism, for which the titania materials is obtained via the replication of a mould such as ordered mesoporous silica, the soft templating pathway is less time consuming and more eco-friendly since it does not require hydrofluoric acid to remove the hard template. A large variety of structure-directing agents such as ionic liquid, poly(ethylene glycol), diblock copolymer, polyoxoethylene fluoroalkyl ether, cyclodextrins or home-made block copolymers (BCPs) have been used to prepare the porous titania material though the soft templating route [18-24]. Nevertheless, among these templates, thanks to their large molecular weights, the triblock copolymers such as Pluronic P123 or F127 are the most widely considered for the preparation of porous $\mathrm{TiO}_{2}[17,25,26]$. Another important point that should be taken into account for the synthesis of templated mesoporous $\mathrm{TiO}_{2}$ concerns the reactivity of the alkoxides, which strongly increases when silicium is replaced by titanium [14]. Different strategies such as the acid-base concept [27], the use of mixed inorganic precursor [28] or hydrolysis controlling agents [29,30] are described in the literature. To control the hydrolysis and condensation of titanium precursors and to avoid its precipitation without interaction with the surfactant, in our group we have developed a synthesis procedure of ordered mesoporous materials, having semi-crystalline framework and with high specific surface area $\left(>250 \mathrm{~m}^{2} / \mathrm{g}\right)$. Our strategy is based on the evaporation-induced self assembly method, usually used for the preparation of the mesoporous films and on the liquid crystal templating mechanism $[18,31]$. We have also succeeded in introducing a second level of porosity and we have shown that thanks to the synergic effect of the presence of the two pore networks, the dual mesoporous titania are more efficient for the photo-degradation of methyl orange, used as model dye, than the mono-modal ones [32]. As described in the experimental part below, in our synthesis procedure an alkaline treatment under $\mathrm{NH}_{3}$ atmosphere is required to complete the condensation of the inorganic precursor prior the surfactant removal 
by extraction. By this way, amorphous $\mathrm{TiO}_{2}$ are recovered and a calcination step is needed to transform the amorphous walls into semi-crystalline ones. Here, we have investigated in detail the influence of the conditions under which these two crucial steps are performed on the properties of the ordered mesoporous $\mathrm{TiO}_{2}$.

\section{Materials and methods}

The triblock copolymer Pluronic P123 $(\mathrm{EO})_{20}(\mathrm{PO})_{70}(\mathrm{EO})_{20}(\mathrm{EO}=$ ethylene oxide, $\mathrm{PO}=$ propylene oxide) was purchased from Aldrich. Titanium isopropoxide $\mathrm{Ti}(\mathrm{OiPr})_{4}(97 \%$ Aldrich) was used as inorganic source. Hydrochloric acid (ACS reagent, 37\%, SigmaAldrich) was employed to control the rate of hydrolysis of the inorganic source.

\subsection{Materials preparation:}

To prepare the mesoporous $\mathrm{TiO}_{2}, 1 \mathrm{~g}$ of P123 was first dissolved in $20 \mathrm{~g}$ of ethanol under stirring at room temperature. Then, $2 \mathrm{~g}$ of a hydrochloric acid solution and $3 \mathrm{~g}$ of titanium isopropoxide $\mathrm{Ti}(\mathrm{OiPr})_{4}$ were added. The mixture was directly evaporated under vacuum to remove ethanol and isopropanol released by hydrolysis of $\mathrm{Ti}(\mathrm{OiPr})_{4}$. Samples were dried in an oven at $40^{\circ} \mathrm{C}$ for $12 \mathrm{~h}$. Then the precipitation of titania in the hybrid mesophase is induced by a treatment under $\mathrm{NH}_{3}$ atmosphere. Two experimental set up have been considered, first after drying the samples were placed in a well-closed glass vessel during 12 hours and concentrated aqueous ammonia (28 wt.\%) was added below the watch glass without touching the sample. Second, the pressure of ammonia and the duration of the treatment under the alkaline atmosphere were varied from 0.5 to 3 bars and from 3 to 24 hours, respectively. In any cases the amorphous $\mathrm{TiO}_{2}$ materials are recovered after ethanol extraction with a Soxhlet apparatus during 16 hours. Then, to transform the amorphous walls into semi-crystalline ones a calcination was performed. The samples were heated to $150^{\circ} \mathrm{C}$, at a rate of $1{ }^{\circ} \mathrm{C} / \mathrm{min}$ and 
kept at this temperature during one hour. Afterwards, the same program was applied to reach the final temperature 300,350 or $380^{\circ} \mathrm{C}$. To investigate the effect of the calcination, all of the process were performed under either nitrogen or synthetic air atmosphere. In a third set of experiments samples were place under nitrogen until reaching the final targeted temperature and then oxygen flow was introduced and the calcination at this step was performed for 1 hour.

2.2. Characterization: Small Angle X-ray Scattering (SAXS) measurements were carried out on a SAXSess $\mathrm{mc}^{2}$ instrument (Anton Paar), using a line collimation system. This instrument is attached to a ID 3003 laboratory X-Ray generator (General Electric) equipped with a sealed X-Ray tube (PANalytical, $\lambda_{\mathrm{Cu}, \mathrm{K} \alpha}=0.1542 \mathrm{~nm}$ ) operating at $40 \mathrm{kV}$ and $50 \mathrm{~mA}$. A multilayer mirror and a block collimator provide a monochromatic primary beam. A translucent beam stop allows the measurement of an attenuated primary beam at $\mathrm{q}=0$. Mesoporous materials were put between two sheets of Kapton ${ }^{\circledR}$ placed in a powder cell before being introduced inside the evacuated chamber. All data were corrected for the background scattering from the Kapton ${ }^{\circledR}$ and for slit-smearing effects by a desmearing procedure from SAXSQuant software using the Lake method. Powder X-ray diffraction patterns were recorded using a PANalytical X'Pert PRO diffractometer equipped with a $\mathrm{Cu}$ X-ray tube $\left(\lambda_{\mathrm{Cu}(\mathrm{K} \alpha)}=0.1542 \mathrm{~nm}\right)$ operating at $45 \mathrm{kV}$ and $40 \mathrm{~mA}$ and a X'Celerator detector. Fixed divergence slit (1/16), mask (10 mm) and antiscatter slit (1/8) were used at primary beam for the current analysis. $\mathrm{N}_{2}$ adsorptiondesorption isotherms were determined on a Micromeritics TRISTAR 3000 sorptometer at $196{ }^{\circ} \mathrm{C}$. The specific surface area was obtained by using the BET model whereas the pore diameter and the pore size distribution were determined by the BJH (Barret, Joyner, Halenda) method applied to the adsorption branch [33]. Raman Scattering Spectra were collected on a Jobin-Yvon T64000 spectrometer equipped with an optical microscope in confocal mode. The 
excitation beam $(514.5 \mathrm{~nm})$ was focused using a long-frontal x50 objective (numerical aperture 0.5 ) on an area of about $3 \mu \mathrm{m}^{2}$. The laser power on the sample was approximately 10 $\mathrm{mW}$. The spectral resolution was $3 \mathrm{~cm}^{-1}$, with a wavenumber precision better than $1 \mathrm{~cm}^{-1}$.

2.3. Photocatalytic activity: Methyl orange was chosen as organic compound to evaluate the photocatalytic properties of the mesoporous titania materials. Analyses have been performed according to the procedure previously reported [34]. In this previous work, we have tested the reproducibility of the system by performing several experiments under the same conditions. The results have shown that the error among three measurements made the same day is usually less than $5 \%$ and is mainly due to light intensity drift. When the experiment was repeated days later, the results did not quantitatively differ from the first results and the trends were similar. Therefore, each experiment was repeated at least three times, and data were considered acceptable only if, for three repetitions, the results for each time point differ by less than $5 \%$. For this purpose, $50 \mathrm{mg}$ of materials have been added to $100 \mathrm{~mL}$ of a methyl orange aqueous solution (16 mg per L). The reaction was carried out under continuous stirring in a quartz flask. Samples were irradiated with UV light from a high-mercury lamp. The irradiation was assured by artificial light using a mercury lamp (low pressure mercury arc, USHIO, light power $7 \mathrm{~W}$ ) emitting in the near-UV. The mean value of the radiation power impinging on the reacting suspension was estimated to be $\mathrm{I}_{\text {incident }}=10^{-5}$ Einstein $\mathrm{L}^{-1} 1 \mathrm{~s}^{-} 1$. Prior to UV irradiation, the aqueous $\mathrm{TiO}_{2}$ suspension containing methyl orange was magnetically stirred in the dark for 1 hour until adsorption/desorption equilibrium was reached. Degradation process of methyl orange was monitored with a Cary 3E UV-Visspectrophotometer. The photocatalytic degradation of methyl orange solution was followed by measuring the absorbance value at $\lambda=464 \mathrm{~nm}$, which allowed access to the methyl orange concentration. Analytical uncertainty on methyl orange concentration was mainly due to the filtration step and has been evaluated to be $1.5 \mu \mathrm{g} \mathrm{L} \mathrm{L}^{-1}$. 


\section{Results and discussion}

\subsection{Influence of the crystallization conditions}

Figure 1 depicts the characteristic of the $\mathrm{TiO}_{2}$ material obtained after ethanol extraction. SAXS analysis shows a hexagonal mesopore ordering since the (100), (110) and (200) reflections are observed on the SAXS pattern (Fig. 1A) at 12.8, 7.3 and $6.5 \mathrm{~nm}$, respectively. The peaks in the range $200-800 \mathrm{~cm}^{-1}$, detected on the Raman spectrum (Fig. 1B), are characteristic of Ti-O-Ti network and are generally observed in all the forms of $\mathrm{TiO}_{2}$ [35]. The presence of an intense peak around $140 \mathrm{~cm}^{-1}$ characteristic of crystalline $\mathrm{TiO}_{2}$ could not be evidenced [36]. The presence of broad peaks in Raman spectrum reveals that the sample is predominantly amorphous. The amorphous titania exhibits a type IV isotherm (Fig. 1C) according to the IUPAC classification [37]. The specific surface area and pore volume values are $400 \mathrm{~m}^{2} / \mathrm{g}$ and $0.65 \mathrm{~cm}^{3} / \mathrm{g}$, respectively. The pore diameter distribution determined by using the $\mathrm{BJH}$ method is quite narrow and centered at ca. $8.4 \mathrm{~nm}$ (Fig. 1D). From the elementary analysis, we can estimate that $19 \%$ of carbon originally contained in the hybrid mesophase still remains in the material after ethanol extraction. So the organic compounds are not completely eliminated upon ethanol extraction.

Whatever the heating conditions, i.e. atmosphere and temperature the mesopore ordering is detected after crystallization (Fig. 2A). Comparing with the SAXS pattern of the extracted $\mathrm{TiO}_{2}$, a shift towards lower value (from 12.8 to $9.0-10.0 \mathrm{~nm}$ ) is noted for the $\mathrm{d}_{100}$ reflections. This phenomenon can be attributed to a condensation of the Ti-OH groups but also to the crystallization of the walls. Indeed, for all samples, Raman spectra displayed in Figure 2B exhibit an intense band in the region $140-155 \mathrm{~cm}^{-1}$. This vibration is consistent with the presence of anatase [38,39], the crystallization of titania has thus occurred. After calcination, the type IV isotherm is still obtained by manometry nitrogen adsorption/desorption. Regardless the atmosphere, $\mathrm{TiO}_{2}$ recovered after calcination at $300^{\circ} \mathrm{C}$ have similar textural 
characteristics (Table 1 and Fig. 3). Their specific surface area, pore volume and mesopore diameter are around $315 \mathrm{~m}^{2} / \mathrm{g}, 0.50 \mathrm{~cm}^{3} / \mathrm{g}$ and $7.7 \mathrm{~nm}$, respectively. Increasing the temperature a drastic effect of this parameter is observed when the calcination is performed under nitrogen following by the exposure to an oxygen flow. As it can be seen in Figure 3Aa, the maximum volume of nitrogen adsorbed at relative pressure $\mathrm{p} / \mathrm{p}_{0}=1$ becomes weaker with the increase of crystallization temperature. Its value drops from 372 to $119 \mathrm{~cm}^{3} / \mathrm{g}-\mathrm{STP}$ if the heating is changed from 300 to $380^{\circ} \mathrm{C}$. Meantime, the specific surface area and the pore volume strongly decrease from 320 to $87 \mathrm{~m}^{2} / \mathrm{g}$ and from 0.53 to $0.15 \mathrm{~cm}^{3} / \mathrm{g}$, respectively (Table 1). Lower values of $\mathrm{dV} / \mathrm{dD}$ are also noted on the mesopore size distribution of the material recovered after calcination at 350 or $380^{\circ} \mathrm{C}$ (Fig. 3Ba). Therefore, even if a mesostructuration is still detected by SAXS, it can be conclude that the collapse of the network has begun. Under synthetic air, taking into account the error on the measurement (about 5\%) it appears that the surface area and the pore volume are not significantly modified with the change of temperature. By contrast, replacing synthetic air by pure nitrogen the specific surface area and the pore volume decrease of about $50 \%$ when the temperature is raised from 300 to $380^{\circ} \mathrm{C}$ (Table 1 ). At same time the $\mathrm{dV} / \mathrm{dD}$ values dropped (Fig. 3Bc), suggesting that the mesostucture also partially collapse, since this variation of $\mathrm{dV} / \mathrm{dD}$ cannot be due to a mesopore blocking by the organic compounds remaining after extraction. Indeed, the elementary analysis shows that only $3.2 \%$ of the total carbon originally detected in the hybrid mesophase remains after crystallization at $380^{\circ} \mathrm{C}$ under nitrogen (Table 2).

After crystallization, the mesoporous titania have been tested for the photodegradation of methyl orange $(\mathrm{MeO})$, used as a model dye. The degradation of the colorant as a function of irradiation time is shown on Figure 4. When crystallizing $\mathrm{TiO}_{2}$ under nitrogen and exposure to an oxygen flow (Fig. 4A), at higher temperature, a faster degradation of the dye is noted. For example after 180 minutes 60,70 and $90 \%$ of $\mathrm{MeO}$ are degraded by the mesoporous 
$\mathrm{TiO}_{2}$ recovered after treatment under nitrogen and exposure to an oxygen flow at 300,350 and $380^{\circ} \mathrm{C}$, respectively. The increment of the photocatalytic activity owing to the increase in temperature can be due to an enhancement of crystallinity. This hypothesis is supported by both XRD (Fig. 5A) and Raman (Fig. 2Ba) analyses. Indeed, increasing the crystallization temperature, the intensity of the diffractions peaks characteristic of anatase is enhanced, reflecting the higher degree of crystallinity. Applying the Scherrer formula [40], the mean size of the crystalline domains $[\mathrm{D}=0.9 \lambda /(\mathrm{w} \cos \theta), \mathrm{w}$ is the width at half maximum of the $(101)$ peak] has been estimated at around $3 \mathrm{~nm}$, after crystallization at 300 and $350^{\circ} \mathrm{C}$ and around 26 $\mathrm{nm}$ after crystallization at $380^{\circ} \mathrm{C}$. The shift from 148 to $143 \mathrm{~cm}^{-1}$ of the Eg mode of anatase (Fig. 2Ba) also indicates the growth of the anatase particles. Indeed, it has been reported that an estimation of a $\mathrm{TiO}_{2}$ crystallite size can be obtained from the position of this vibration $[38,41,42]$. Eg mode appears at $143 \mathrm{~cm}^{-1}$ in bulk anatase and shifts to higher wavenumbers in nanocrystalline materials. The evolution of the textural parameters also suggests the growth of the anatase particles, which involves a partial collapse of the mesostucture. Enhancement of photoactivity with crystallinity has been described in the literature [43-45]. For example, Ohtani et al. [45] have reported that higher crystallinity of the anatase phase enhanced drastically the photocatalytic activity of $\mathrm{TiO}_{2}$ materials. In addition, even if whatever the calcination conditions Raman analyses reveal the presence of anatase (Eg modes at 145-150 $\mathrm{cm}^{-1}$ and $198 \mathrm{~cm}^{-1}$ ), the appearance of a peak at around $250 \mathrm{~cm}^{-1}$ (Fig. 2Ba) after heating at $300^{\circ} \mathrm{C}$ shows also the existence of rutile (combination mode) [39], which is unfavorable for photocatalysis. Indeed, among the common crystalline forms of titania, anatase is recognized to be the most active phase and rutile thermodynamically the most stable [46]. However as soon as the particles size is below $10-15 \mathrm{~nm}$ anatase is more stable [47-49]. So here, one can expect to detect only anatase by Raman. The presence of rulile can arise from the treatment made under ammonia to complete the condensation of the titanium precursor. Indeed, in 
papers dealing with the surfactant-assisted synthesis of mesoporous titania with monocrystalline anatase walls, Cassiers et al. [50,51] have performed a $\mathrm{NH}_{3}$ treatment in a reflux system not to control the mesostructuration, but to enhance both the thermal stability and the crystallinity of the synthesized mesoporous wormhole-like titania. The authors report that during the heat treatment, the adsorbed ammonia molecules inside the pores promote the transformation of the amorphous walls into rutile at low temperature (in the range 200$300^{\circ} \mathrm{C}$ ). Increasing further the temperature to remove the template, the amorphous titania particles, which were not in interaction with $\mathrm{NH}_{3}$, are transformed into anatase without collapse of the mesopores. By this way the mesostructure is maintained thanks to the incorporation of the nanosized rutile particles in the walls. Because of the small size of the crystallites, the presence of rutile cannot be observed by XRD and it has been evidenced only by Raman spectroscopy, which is a more sensitive technique for detection of nanosized crystalline domains [51]. Fu et al. [52,53] have developed a similar post-synthesis procedure replacing ammonia by ethylenediamine for the preparation of porous $\mathrm{TiO}_{2}$ nanoparticles. The interaction between titania and $\mathrm{NH}_{3}$ has been widely used in literature to prepare nitrogendoped $\mathrm{TiO}_{2}$ by mechanochemical reaction [54-56]. In our study, we can assume that such a phenomenon also takes place to justify the formation of rutile. This hypothesis is strengthened by the elementary analysis, which shows that $7.2 \%$ of nitrogen are incorporated into the hybrid mesophase. Since, the surfactant, the solvent and the titanium precursor content no nitrogen atoms, its origin arise from ammonia, which can adsorb at the surface of titania through Lewis acid adsorption mechanism. After extraction $4 \%$ of nitrogen, i.e around $50 \%$ of $\mathrm{N}$ detected in the hybrid mesophase, are still present in the amorphous $\mathrm{TiO}_{2}$. So, it can be inferred that the same scheme than the one reported by Cassiers et al. [50,51] occurs upon crystallization. The amorphous titania in interaction with $\mathrm{NH}_{3}$ are transformed into rutile and the «free» amorphous $\mathrm{TiO}_{2}$ gives rise to anatase, which is the more stable phase at the 
nanosized level. Since the crystallinity of anatase increases with temperature, its Raman signature is exalted and rutile is not detected any longer. Another parameter that can be considered to understand the lower activity when the calcination is performed at $300^{\circ} \mathrm{C}$, deals with the presence of the amorphous phase, which comprises numerous defects, i.e., impurities, dangling bonds, and microvoids that can behave as recombination centers for the photoinduced electron/hole $\left(\mathrm{e}^{-} / \mathrm{h}^{+}\right)$pairs [45].

In terms of photodegradation efficiency, the mesoporous titania recovered after crystallization under synthetic air (Fig. 4B) follow the same trend than the ones crystallized under nitrogen and exposure to an oxygen flow. Nevertheless, it should be noted that in that case for a given temperature a lower activity is obtained. $65 \%$ of methyl orange are degraded within 180 minutes by $\mathrm{TiO}_{2}$ crystallized under synthetic air against $90 \%$ by titania calcined under nitrogen and exposure to an oxygen flow. This difference of behavior can be ascribed to a lower crystallinity of the anatase. Indeed, peaks detected on the XRD pattern are less resolved (Fig. 5Bb) and they have a lower intensity than the ones of the anatase obtained after calcination under nitrogen followed by exposure to oxygen. In addition, the position of the Eg mode at around $148 \mathrm{~cm}^{-1}$ (against $143 \mathrm{~cm}^{-1}$ ) is consistent with the formation of smaller anatase particles under synthetic air. This difference of crystallinity degree can be attributed to the lower content of oxygen in synthetic air. In fact, the formation and the growth of anatase particles are not favored at low oxygen content $[57,58]$. However, the shift of the Eg mode from 150 to $148 \mathrm{~cm}^{-1}$ (Fig. 2Bc), when the crystallization temperature increases from 300 to $380^{\circ} \mathrm{C}$, suggests that larger particles are formed when the temperature is raised. The possible presence of residual organic molecules in the pores, which trap photo-generated electrons at the surface of $\mathrm{TiO}_{2}$ and prevent the degradation of methyl orange in solution, can also contribute to this lower activity. Indeed, after calcination under air synthetic at 300,350 and $380^{\circ} \mathrm{C}$ respectively $8.6,14.5$ and $2.2 \%$ of $\mathrm{C}$ still remain in the photocatalyst (Table 2). 
By contrast, when the crystallization occurs under nitrogen and exposure to an oxygen flow at 300,350 and $380^{\circ} \mathrm{C}$ the residual carbon content is evaluated to $8.2 \%$ after treatment at $300^{\circ} \mathrm{C}$ but less than $0.2 \%$ after heating at 350 or $380^{\circ} \mathrm{C}$ (Table 2). The residual carbon contained in the titania calcined under synthetic air is a drawback for the photocatalysis efficiency but it can prevent the pores from collapsing [59].

Looking at the photocatalytic efficiency of the mesoporous $\mathrm{TiO}_{2}$ crystallized under pure nitrogen, the situation is quite different (Fig. 4C). In that case, rutile is still detected even after calcination at $380^{\circ} \mathrm{C}$ (Fig. 2Bc). The absence of oxygen during the crystallization, is a drawback for the growth of anatase particles [57,58]. XRD pattern (Fig. 5Bc) and Raman spectra (Fig. 2Bc) support this fact. Comparing with crystallization under oxidizing conditions, less resolved reflections with lower intensity are obtained upon calcination under pure nitrogen. Since after crystallization at $380^{\circ} \mathrm{C}$ the position of the Eg mode on the Raman spectra varies from 143,148 and $151 \mathrm{~cm}^{-1}$ when nitrogen followed by exposure to oxygen flow, air synthetic and pure nitrogen are used as atmosphere, respectively it can be assume that the smallest anatase particles are obtained under pure nitrogen. The evolution of the activity as a function of temperature cannot be correlated to the carbon loading in the materials since the carbon content is equal to $8.1,8.3$ and $3.2 \%$ for a calcination temperature of 300,350 and $380^{\circ} \mathrm{C}$, respectively. Using photocatalysts crystallized under this atmosphere, the methyl orange degradation is not governed by the anatase particles but by the specific surface area, which decreases from 313 to $150 \mathrm{~m}^{2} / \mathrm{g}$ when the temperature increases from 300 to $380^{\circ} \mathrm{C}$. In fact, the photodegradation rate of the dye follows the same trend than the variation of $\mathrm{S}_{\mathrm{BET}}$. This is because a larger surface area provides more active sites for adsorbing methyl orange molecules. 


\subsection{Influence of the hybrid mesophase treatment under $\mathrm{NH}_{3}$ atmosphere}

Until now, to complete the polycondensation of the titanium precursor, the hybrid mesophase was placed in a well-closed glass vessel during 12 hours. Concentrated aqueous ammonia (28 wt.\%) was added below the watch glass without touching the sample. $\mathrm{NH}_{3}$ pressure is thus not well controlled. To shed some light on the exposition of the hybrid mesophase to ammonia atmosphere on the mesoporous titania properties, we have performed this step under welldefined ammonia pressure. As depicted in Figure 6A, whatever the duration, a hexagonal mesopore ordering is obtained when the ammonia pressure is fixed to 0.5 bar. Indeed, three more or less well-resolved reflection peaks can be observed on all samples. As example after 12 hours the peaks corresponding to d-spacings $11.9,6.7$ and $5.9 \mathrm{~nm}$ detected on the SAXS pattern can be attributed to (100), (110) and (200) plane reflections that indicate a hexagonal structure with a cell parameter $\mathrm{a}_{0}$ of $13.7 \mathrm{~nm}$. A slight increase of $\mathrm{a}_{0}$ from 13.6 to $14.4 \mathrm{~nm}$ is noted when the treatment duration under the alkaline atmosphere varies from 3 to 24 hours. Extracted samples have a type IV isotherm (Fig. 7Aa), characterizing mesoporous materials. Above the relative pressure of 0.5 we can observe a rather $\mathrm{H} 1$ hysteresis loop. A slight decrease of the specific surface area accompanied by an increase of both the pore volume and the mesopore diameter from 0.42 to $0.62 \mathrm{~cm}^{3} / \mathrm{g}$ and from 9.8 to $10.4 \mathrm{~nm}$, respectively, is noted as a function of time (Table 3). It can also be noted that when the exposure to $\mathrm{NH}_{3}$ is prolonged the pore size distribution becomes narrower and the $\mathrm{dV} / \mathrm{dD}$ values increase (Fig. 7Ba), suggesting a better homogeneity of the mesopore diameter. This is also reflecting by the capillary condensation step, which is more abrupt.

If the ammonia pressure is increased, we can notice that all SAXS patterns exhibited the characteristics of a hexagonal 2D structure until 1.5 bar (Fig. 6B). However, the peaks (110) and (200) are barely distinguishable by extending the alkaline treatment, indicating a less ordered channel arrangement. Above 1.5 bar, only short duration (less than 6 hours) can lead 
to ordered mesopores network. Applying a longer stay under $\mathrm{NH}_{3}$ atmosphere, only one broad reflection, which position shifts towards higher value with the ammonia pressure, is observed (Fig. 6C). These kinds of patterns indicate that the channels adopt a wormhole-like structure. The position of the peak gives an indication of the average pore-pore distance in the disordered wormhole framework, which lacks long-range crystallographic order. All the isotherms are type IV, when considering the IUPAC classification (Fig. 7Ab, 7Ac). A H2 type hysteresis loops between the adsorption and desorption curves, encountered for disordered materials with a wormhole structure is observed with the increase of both the ammonia pressure and the treatment duration (Fig. 7Ab, 7Ac). No significant variations of the specific surface area and of the pore volume are noted when the conditions of exposure under $\mathrm{NH}_{3}$ atmosphere are modified. They remain in the ranges $300-400 \mathrm{~m}^{2} / \mathrm{g}$ and $050-0.70 \mathrm{~cm}^{3} / \mathrm{g}$, respectively (Table 3). Surprising, above 0.5 bar, a second component appear in the mesopore size distribution when the pressure or the duration is increased (Fig 7Bb, 7Bc and Table 3). As long as the hexagonal mesopore ordering is detected, the wall thickness, calculated by subtracting the mesopore diameter to the cell parameter is constant, around $4 \mathrm{~nm}$, whatever the ammonia pressure of and the duration of the treatment (Table 3).

When titanium isopropoxide $\mathrm{Ti}(\mathrm{OiPr})_{4}$ is used as precursor to synthesize $\mathrm{TiO}_{2}$ according to the sol-gel process both the hydrolysis and polycondensation reactions occur simultaneously in water $[60,61]$. These reactions are sensitive to preparation conditions such as the amount of solvent, water, $\mathrm{pH}$ and so on. In particular, in strong acidic media or in the presence of polar solvents the process is significantly inhibited. In our synthesis procedure, this allows avoiding the precipitation of the titanium alkoxide prior its interaction with the surfactants. According to Sanchez et al. [62], after the dissolution of $\mathrm{Ti}(\mathrm{OiPr})_{4}$ fast exchange reactions with ethanol $(\mathrm{EtOH})$ and $\mathrm{HCl}$ molecules occur, involving the formation of $\mathrm{Ti}(\mathrm{OiPr})_{4-\mathrm{x}}(\mathrm{OEt})_{\mathrm{x}}$ or $\mathrm{TiCl}_{4-}$ ${ }_{\mathrm{x}}(\mathrm{OEt})_{\mathrm{x}}$ species or a mixture of both. After polycondensation $\mathrm{TiX}_{4}(\mathrm{OH})_{\mathrm{y}} \mathrm{O}_{2-(\mathrm{x}+\mathrm{y}) / 2}(\mathrm{X}=\mathrm{OiPr}$ or 
$\mathrm{Cl}^{-}$) metaloxo condensates are formed. During the synthesis of the mesoporous $\mathrm{TiO}_{2}$, hydrogen bonding interactions occur between these species and the Pluronic P123 leading to the hybrid mesophases. However, after solvent removal and drying in an oven at $40^{\circ} \mathrm{C}$ for 12 $\mathrm{h}$, no material can be recovered after ethanol extraction since both the organic and inorganic species are dissolved. This suggests that the condensation of the titanium clusters around the liquid crystal is incomplete likely due to the presence of $\mathrm{Cl}^{-}$, arising from the acid, at the interface [26]. The presence of chlorine in the hybrid mesophase has been identified in a previous study [63]. This behavior is similar to what it is observed for mesoporous thin film prepared from $\mathrm{TiCl}_{4}$ precursor in the presence of $\mathrm{F} 127$ or Brij 58 surfactants after the drying at room temperature [64]. Concerning the preparation of the mesoporous $\mathrm{TiO}_{2}$, when the hybrid mesophase is placed under the ammonia atmosphere, $\mathrm{NH}_{3}$ and water adsorb at the titania/surfactant interface and therefore the media become more alkaline enhancing the condensation. $\mathrm{NH}_{3}$ and $\mathrm{Cl}^{-}$can also react to form $\mathrm{NH}_{4} \mathrm{Cl}$, by the way the $\mathrm{Cl}^{-}$ions located at the interface, which prevent the condensation of the titania clusters, will be moved away from the interface, allowing the polycondensation to go on. $\mathrm{NH}_{4} \mathrm{Cl}$ will be removed during the extraction and calcination steps. However, since ammonia is hydrophilic it can also interact with the surfactant head group, disturbing the hydrogen bonding interactions between P123 and the metaloxo condensate. Therefore, when the $\mathrm{NH}_{3}$ pressure is increased or when the treatment under the ammonia atmosphere is prolonged the channel array can be affected and a wormhole-like mesostucture is obtained, as observed by SAXS analysis. In addition, the channel array can also be disorganized because of the possible interaction between ammonia and titanium. Indeed as mentioned above, electrophilic metals capable of increasing their coordination number can interact with ammonia via the Lewis acid adsorption mechanism. This property has been widely exploited for the deposition of $\mathrm{TiO}_{2}$ films at low temperature with titanium isopropoxide as a reactant using $\mathrm{NH}_{3}$ as catalyst $[65,66]$. 
In an analog way to what it is reported in the case of mesoporous silica materials [67-69], the slight increase of the mesopore size observed when the alkaline treatment is performed at 0.5 bar can also be explained by a swelling of the channel by $\mathrm{NH}_{3}$ molecules. For example papers dealing with the characterization of pore systems of mesoporous silicas templated by cetylpyridinium under mild-alkaline condition, Yuan et al. explained that due to its volatility, ammonia molecules should penetrate inside the nanochannels more easily than water, leading to the pore size expansion $[67,68]$. In the same articles, the authors consider a decomposition of the surfactant after hydrothermal treatment to justify the bimodality detected after this step. Here, since no heating treatment is performed at this stage, such phenomenon cannot be taken into account to explain the second component observed in the mesopore size distributions with the increase of the ammonia pressure. Since the two maxima are very closed to each other, only one inflection point, related to the capillary condensation step, is detected on the isotherm. We can assume that this dual porosity is rather a consequence of the diffusion of the ammonia molecules, which provoke a heterogeneous size expansion of the cylinders of the $\mathrm{H}_{1}$ liquid crystal.

To evaluate the photocatalytic efficiency of the mesoporous titania for the photodegradation of methyl orange, the samples treated at different $\mathrm{NH}_{3}$ pressures $(0.5,1,1.5$ and 2 bars $)$ during 6 hours, have been calcined at $380^{\circ} \mathrm{C}$ under synthetic air. From the results above these crystallization conditions seem to be a good compromise between maintaining the mesostucture and the photodegradation efficiency. The photocatalytic degradation of methyl orange using the crystallized catalysts is displayed in Figure 8. The photodegradation rate decreases with the $\mathrm{NH}_{3}$ pressure applied during the polycondensation step. Since all the calcined materials have specific surface area in the same range of order, around $250 \mathrm{~m}^{2} / \mathrm{g}$, this is not the main parameter that affects the photocatalytic activity. However, when the ammonia pressure at which the hybrid mesophase is exposed increases, a decrease of the band gap of 
the calcined material from 2.9 to $2.7 \mathrm{eV}$ is noted (Fig. 9A). The band gap energies have been determined from the UV spectra according to a method previously described [63]. From Table 4 it can also be seen that whatever the $\mathrm{NH}_{3}$ pressure, applied during the treatment of the hybrid mesophase, the amounts of nitrogen and carbon in the calcined mesoporous titania are almost constant to 1.5 and $1.4 \%$, respectively. The variations of band gap and of the photodegradation efficiency cannot thus be relied to a doping of the $\mathrm{TiO}_{2}$ by these elements as reported in literature [70], for example when powder $\mathrm{TiO}_{2}$ is treating in a $\mathrm{NH}_{3}$ gas flow. In that case, $\mathrm{N}$-doping induces oxygen vacancies and contributes to the absorption as well as photoactivity in the visible region. It is also reported that modified $\mathrm{N}$ doped $\mathrm{TiO}_{2}$ such as $\mathrm{C}$ $\mathrm{N}-\mathrm{TiO}_{2}$, usually shows favorable effects for improving the vis-photocatalytic activity compared to $\mathrm{N}$-doped $\mathrm{TiO}_{2}$ [70]. However, even if we cannot completely exclude that in our study such a phenomenon occurs, the constant values of the nitrogen and carbon contents in the $\mathrm{TiO}_{2}$ materials used for the photodegradation experiments indicate that this is not the main factor explaining both the decrease of the band gap energy (Fig. 9A) and of the photodegradation efficiency (Fig. 8). In addition, here, when the ammonia pressure at which the hybrid mesophase is exposed increases, a decrease of anatase crystallinity is observed (Fig. 9B). Indeed, in the bare $\mathrm{TiO}_{2}$ material recovered after solvent extraction and calcination under synthetic air, peaks characteristic of anatase are less intense when the hybrid mesophase has been submitted to a higher ammonia pressure. Meantime on the Raman spectra, besides the vibration of anatase the combination band, the $E_{g}$ and $A_{1 g}$ of rutile [39] appear at around 251, 435 and $613 \mathrm{~cm}^{-1}$ (Fig. 9C), respectively. Therefore, both the decay of the photodegradation efficiency and of the band gap energy can be related to the presence of rutile. With increasing, the $\mathrm{NH}_{3}$ pressure at which the hybrid mesophase is exposed more and more $\mathrm{NH}_{3}$ molecules are likely adsorbed at the surface of the amorphous titania and upon crystallization the later transformed into rutile and as a consequence less «free» amorphous 
$\mathrm{TiO}_{2}$ are available to give rise to anatase. This fact is supported by the increase of the nitrogen content in the hybrid mesophase from 5.3 to $6 \%$, when the ammonia pressure varies from 0.5 to 2.5 bar.

It should be also noted that a higher photodegradation efficiency is obtained for the photocatalysts crystallized under the same conditions but for which the hybrid mesophase has been exposed to an ammonia atmosphere arising from concentrated aqueous ammonia (28 wt.\%). For this $\mathrm{TiO}_{2}$ material Raman spectroscopy does not show trace of rutile (Fig. 2Bb). Since in that case the hybrid mesophase is not submitted to an ammonia flow, probably less interaction between $\mathrm{NH}_{3}$ and amorphous titania occurs.

\section{Conclusions}

In this study we have investigated the crystallization conditions of amorphous $\mathrm{TiO}_{2}$ on the properties of the final photocatalyst. Prior to calcination, the organic compounds have been removed by ethanol extraction. From the elementary analysis, it is found that around $19 \%$ of carbon originally contained in the hybrid mesophase still remain in the material after ethanol extraction. Nitrogen is also detected both in the hybrid mesophase and in the extracted $\mathrm{TiO}_{2}$. Since, the surfactant, the solvent and the titanium precursor content no nitrogen atoms, its origin arises from ammonia, which can adsorb at the surface of titania through Lewis acid adsorption mechanism. This interaction between amorphous titania and $\mathrm{NH}_{3}$ promote the formation of rutile, which coexist with anatase at $300^{\circ} \mathrm{C}$. Whatever the atmosphere and the temperature SAXS show the presence of a mesopore ordering. However when the heat treatment is performed under nitrogen followed by an exposure to oxygen flow the textural properties suggest that the mesostucture collapses with the increasing crystallization temperature. Such a phenomenon does not occur under synthetic air. Under oxidizing atmosphere, thanks to an enhancement of crystallinity and to a growth of the anatase particles, 
the rate of methyl orange degradation increased with the temperature at which the photocatalyst is crystallized. By contrast, under pure nitrogen transformation, amorphous $\mathrm{TiO}_{2}$ into anatase is not favored and the efficiency follows the same evolution than the specific surface area of the material since large surface area provides more active sites for adsorbing dye molecules. The optimum crystallization conditions seem to be $380^{\circ} \mathrm{C}$ under synthetic air.

In a second part, we have shed some lights on the influence of the treatment of the hybrid mesophase under ammonia atmosphere, performed prior extraction and crystallization. With increasing $\mathrm{NH}_{3}$ pressure or the duration of this treatment, interactions between ammonia and titania but also with the surfactant head group disturb the ones between P123 and titanium precursor. By this way a wormhole like structure is obtained. The amorphous $\mathrm{TiO}_{2}-\mathrm{NH}_{3}$ interactions are also responsible for the promotion of the rutile. So, when calcined under synthetic air at $380^{\circ} \mathrm{C}$, after exposure of the hybrid mesophase at high ammonia pressure or for long time, less amorphous $\mathrm{TiO}_{2}$ is available to be transformed into anatase. Consequently, the final photocatalysts are less efficient for the photodegradation of methyl orange. 


\section{References}

[1] M. Hoffmann, S.Martin, W. Choi, D. Bahnemann Chem. Rev. 95 (1995) 69-96.

[2] A. Linsebigler, G. Lu, J. Yates Chem. Rev. 95 (1995) 735-758.

[3] M. Fox, M. Dulay Chem. Rev. 93 (1993) 341-357.

[4] X. Chen, S.S. Mao Chem. Rev. 107 (2007) 2891-2959.

[5] K.I. Hadjiivanov, D.G. Klissurski Chem. Soc. Rev. 25 (1996) 61-69.

[6] D.A. Panayotov, J.R. Morris Surf. Sci. Rep. 71 (2016) 77-271.

[7] J. Li, W. Ma, C. Chen, J. Zhao, H. Zhu, X. Gao J. Mol. Catal. A : Chem. 261 (2007) 131-138.

[8] M. Yin, Z. Li, J. Kou, Z. Zhou Environ. Sci. Technol. 43 (2009) 8361-8366.

[9] P. Castillo-Villalón, J. Ramírez J. Catal. 268 (2009) 39-48.

[10] Y. Jiang, W. Tang, J. Gao, L. Zhou, Y. He Enzyme Microb. Technol. 55 (2014) 1-5.

[11] J. Wei, Z.T. Jiang, S. Jiang, R. Li, J. Tan J. Liq. Chromatogr. Relat. Technol. 36 (2013) 1616-1630.

[12] S. Rasalingam, C.M. Wu, R.T. Koodali ACS Appl. Mater. Interfaces 7 (2015) 43684380.

[13] R. Zhang, A.A. Elzatahry, S.S. Al-Deyab Nano Today 7 (2012) 344-366.

[14] W. Li, Z. Wu, J. Wang, A.A. Elzatahry, D. Zhao Chem. Mater. 26 (2014) 287-298

[15] S. Bagheri, Z.A.M. Hir, A.T. Yousefi, S.B.A. Hamid Microporous Mesoporous Mater. 218 (2015) 206-222.

[16] T. Kimura Chem. Rec. 16 (2016) 445-457.

[17] A.A. Ismail, D.W. Bahnemann J. Mater. Chem. 21 (2011) 11686-11707.

[18] K. Zimny, J. Ghanbaja, C. Carteret, M.J. Stébé New J. Chem. 34 (2010) 2113-2117. 
[18] J. Veliscek-Carolan, R. Knott, T. Hanley J. Phys. Chem. C 119 (2015) 7172-7183.

[20] A. Lannoy, R. Bleta, C. Machut, E Monflier, A. Ponchel, RSC. Adv. 4 (2014) 40614070.

[21] S. Cao, Y. Zhao, T. Qu, P. Wang, S. Guan, Y. Xu, F. Rao, Y. Li, A. Chen, T. Lyoda RSC Adv. 6 (2016) 55834-55841.

[22] J. Lee, M.C. Orilall, S. C. Warren, M. Kampermann, F.J. Disalvo, U. Wiesner Nat. Mater. 7 (2008) 222-228.

[23] P. Preethi, M.P. Padmapriya, B. Abarna, G.R. Rajarajeswari, RSC. Adv. 7 (2017) 10081-10091.

[24] D. Nguyen, W. Wang, H. Long, H. Ru Front. Mater. Sci. 10 (2016) 405-412.

[25] P. Yang, D. Zhao, D.I. Margolese, B.F. Chmelka, G.D. Stucky Nature 396 (1998) 152155.

[26] P. Yang, D. Zhao, D.I. Margolese, B.F. Chmelka, G.D. Stucky Chem. Mater. 11 (1999) 2813-2826.

[27] B. Tian, X. Liu, B. Tu, C. Yu, J. Fan, L. Wang, S. Xie, G.D Stucky, D. Zhao Nature Mater. 2 (2003) 159-163.

[28] B.Tian, H. Yang, X. Liu, S. Xie, C.Yu, J. Fan, B. Tu, D. Zhao Chem. Commun. 17(2002) 1824-1825.

[29] H. Li, J.L. Shi, J. Liang, X. Li, L. Li, M. Ruan Mater. Lett. 62 (2008) 1410-1413.

[30] D.T. On, Langmuir 15 (1999) 8561-8564.

[31] K. Zimny, C. Carteret, M.J. Stébé, J.L. Blin J. Phys. Chem. C 116 (2012) 6585-6594. 
[32] Naboulsi, B. Lebeau, L. Michelin, C. Carteret, L. Vidal, M. Bonne, J.L. Blin, ACS Appl. Mater. Interfaces 9 (2017) 3113-3122.

[33] E.P. Barrett, L.G. Joyner, P.P. Halenda, J. Am. Chem. Soc. 73 (1951) 373-380.

[34] J.L. Blin, M.J. Stébé, T. Roques-Carmes, Colloids Surf. A 407 (2012) 177-185.

[35] Z.W. Seh, S. Liu, M. Low, S.Y. Zhang, Z. Liu, A. Mlayah, M.Y. Han, Adv. Mater. 24 (2012) 2310-2314.

[36] B. Luo, Z. Li, Y. Xu, RSC Adv. 5 (2015) 105999-106004.

[37] K.S.W. Sing, D. H. Everett, R. A. W Haul, L. Moscou, R. A. Pierotti, J. Rouquerol, T. Siemieniewska, IUPAC, Pure and Appl. Chem. 57 (1985) 603-619.

[38] S. Kelly, F.H. Pollak, M. Tomkiewicz, J. Phys. Chem. B 101 (1997) 2730-2734.

[39] A. Mattsson, L. Österlund, Phys. Chem. C 114 (2010) 14121-14132.

[40] H.P. Klug, L.E. Alexander in X-ray Diffraction Procedures, Wiley (Eds), New York, 1954, ch. 9.

[41] W.F. Zhang, Y.L. He, M.S. Zhang, Z. Yin, Q. Chen, J. Phys. D: Appl. Phys. 33 (2000) 912-916.

[42] A. Pottier, S. Cassaignon, C. Chanéac, F. Villain, E. Tronc, J.P. Jolivet, J. Mater. Chem. 13 (2003) 877-882.

[43] D.S. Kim, S.J. Han, S.Y. Kwak, J. Colloid Interface Sci. 316 (2007) 85-91.

[44] V.F. Stone Jr, R.J. Davis, Chem. Mater. 10 (1998) 1468-1474.

[45] B. Ohtani, Y. Ogawa, S. Nishimoto, J. Phys. Chem. B 101 (1997) 3746-3752.

[46] O. Carp, C.L. Huisman, A. Reller, Prog. Solid State Chem. 32 (2004) 33-177.

[47] H. Zhang, J.F. Banfield, J. Phys. Chem. B 104 (2000) 3481-3487. 
[48] A.A. Gribb, J.F. Banfield, Am. Mineral. 82 (1997) 717-728.

[49] A. Feldhoff, C. Mendive, T. Bredow, D. Bahnemann, ChemPhysChem 8 (2007)805809.

[50] K. Cassiers, T. Linssen, V. Meynen, P. Van Der Voort, P. Cool, E.F. Vansant, Chem. Commun, 10 (2003) 1178-1179.

[51] K. Cassiers, T. Linssen, M. Mathieu, Y.Q. Bai, H.Y. Zhu, P. Cool, E.F. Vansant, J. Phys. Chem. B 108 (2004) 3713-3721.

[52] G. Tian, H. Fu, L. Jing, B. Xin, K. Pan, J. Phys. Chem. C 112 (2008) 3083-3089.

[53] W. Zhou, F. Sun, K. Pan, G. Tian, B. Jiang, Z. Ren, C. Tian, H. Fu, Adv. Funct. Mater. 21 (2011) 1922.1930.

[54] X. Pan, X. Ma, J. Solid State Chem. 177 (2004) 4098-4103.

[55] I.C. Kang, Q. Zhang, J. Kano, S. Yin, T. Sato, F. Saito, J. Photochem. Photobiol., A 189 (2007) 232-238.

[56] G. Liu, F. Li, Z. Chen, C.Q. Lu, H.M. Cheng, J. Solid State Chem. 179 (2006) 331335.

[57] V.M. Kalygina, I.M. Egorova, V.A. Novikov, I.A. Prudaev, O.P. Tolbanov, semiconductors 50 (2016) 1156-1162.

[58] R. Pandian, G. Natarajan, S. Rajagopalan, M. Kamruddin, A.K. Tyagi, Appl. Phys. A 116 (2014) 1905-1913.

[59] J. Tang, Y. Wu, E.W. McFarland, G.D. Stucky, Chem. Commun, 14 (2004) 16701671. 
[60] K. Terabe, K. Kato, H. Miyazaki, S. Yamaguchi, A. Imai, Y. Iguchi, J. Mater. Sci. 29 (1994) 1617-1622.

[61] B.E. Yoldas, J. Mater. Sci. 21 (1986) 1087-1092.

[62] G.J. De A. A. Soller-Illia, C. Sanchez, New. J. Chem. 24 (2000) 493-499.

[63] K. Assaker, B. Lebeau, L. Michelin, P. Gaudin, C. Carteret, L. Vidal, M. Bonne, J.L. Blin, J. Alloys Compd. 649 (2015) 1-10.

[64] D. Grosso, G.J. De A. A. Soller-Illia; F. Babonneau, C. Sanchez, P.A. Albouy, A. Brunet-Bruneeau, A. R. Balkenade, Adv. Mater. 13 (2001) 1085-1090.

[65] S.H. Jung, S.W. Kang, Jpn. J. Appl. Phys. 40 (2001) 3147-3152.

[66] X. Song, C. G. Takoudis, J. Vac.Sci. Technol. A. 25 (2007) 360-367.

[67] Z.Y. Yuan, J.L. Blin, B.L. Su, Chem. Commun, 5 (2002) 504-505.

[68] Z.Y. Yuan, B.L. Su, Colloids Surf. A 241 (2004) 95-102.

[69] R. Xing, S.E. Rankin, Microporous Mesoporous Mater. 108 (2008) 65-76.

[70] J. Zhang, Y. Wu, M. Xing, S.A.K. Leghari, S. Sajjad, Energy Environ. Sci. 3 (2010) 715-726. 


\section{Figures caption}

Figure 1: $\quad$ SAXS pattern (A), Raman spectrum (B), nitrogen adsorption-desorption isotherm (C) and pore size distribution (D) of $\mathrm{TiO}_{2}$ recovered after ethanol extraction.

Figure 2: Evolution of the SAXS pattern (A) and of the Raman spectrum (B) as a function of the calcination conditions. Crystallization is performed under nitrogen following by exposure to oxygen flow (a), synthetic air (b) and pure nitrogen (c).

Figure 3: Nitrogen adsorption-desorption isotherms (A) and mesopore size distribution (B) of the titania recovered after calcination at different temperature under nitrogen following by exposure to oxygen flow (a), synthetic air (b) and pure nitrogen (c).

Figure 4: Change in the concentration of methyl orange as a function of the time of irradiation for crystallized mesoporous $\mathrm{TiO}_{2}$ under nitrogen following by exposure to oxygen flow (A), synthetic air (B) and pure nitrogen (C).

Figure 5: $\quad$ XRD patterns of the crystallized mesoporous $\mathrm{TiO}_{2}$. Samples are calcined under nitrogen following by exposure to oxygen flow at different temperatures (A) or at $380^{\circ} \mathrm{C}(\mathrm{B})$ under nitrogen following by exposure to oxygen (a), synthetic air (b) and pure nitrogen (c).

Figure 6: Evolution of the SAXS pattern as a function of the exposition duration of the hybrid mesophase under ammonia atmosphere for a $\mathrm{NH}_{3}$ pressure of $0.5(\mathrm{~A})$, 1.5 (B) and 2.5 bar (C).

Figure 7: Nitrogen adsorption-desorption isotherms (A) and mesopores size distributions (B) as a function of the exposition duration of the hybrid mesophase under ammonia atmosphere for a $\mathrm{NH}_{3}$ pressure of 0.5 (a), 1.5 (b) and 2.5 bar (c). 
Figure 8: Change in the concentration of methyl orange as a function of the time of irradiation for titania crystallized at $380^{\circ} \mathrm{C}$ under synthetic air. Prior to extraction and calcination, the hybrid mesophase has been exposed to various ammonia pressures during 6 hours.

Figure 9: Band gap energy (A), XRD patterns (B) and Raman spectra (C) of titania crystallized at $380^{\circ} \mathrm{C}$ under synthetic air. Prior to extraction and calcination, the hybrid mesophase has been exposed to various ammonia pressures during 6 hours. 
Table 1 : Repetition distance $(d)$, cell parameter $\left(a_{0}\right)$, specific surface area $\left(S_{\mathrm{BET}}\right)$, total pore volume $\left(\mathrm{V}_{\mathrm{P}}\right)$, pore diameter $(\varnothing)$ and wall thickness (e) of the material obtained after crystallization

\begin{tabular}{|c|c|c|c|c|c|c|c|}
\hline \multirow[b]{2}{*}{ Atmosphere } & \multicolumn{3}{|l|}{ Temperature } & \multirow[b]{2}{*}{$\begin{array}{c}\mathrm{S}_{\mathrm{BET}} \\
\left(\mathrm{m}^{2} / \mathrm{g}\right)\end{array}$} & \multirow[b]{2}{*}{$\begin{array}{c}\mathrm{Vp} \\
\left(\mathrm{cm}^{3} / \mathrm{g}\right)\end{array}$} & \multirow[b]{2}{*}{$\begin{array}{c}\varnothing \\
(\mathrm{nm})\end{array}$} & \multirow[b]{2}{*}{$\begin{array}{c}\mathrm{e} \\
(\mathrm{nm})\end{array}$} \\
\hline & $\left({ }^{\circ} \mathrm{C}\right)$ & $\mathrm{d}(\mathrm{nm})$ & $\begin{array}{c}\mathrm{a}_{0} \\
(\mathrm{~nm})\end{array}$ & & & & \\
\hline \multirow{3}{*}{$\mathrm{N}_{2}$} & 300 & 9.8 & 11.3 & 313 & 0.50 & 7.7 & 3.6 \\
\hline & 350 & 9.5 & 11.0 & 285 & 0.50 & 7.0 & 4.0 \\
\hline & 380 & 9.5 & 11.0 & 150 & 0.22 & 7.0 & 4.0 \\
\hline \multirow{3}{*}{ Synthetic } & 300 & 10.0 & 11.5 & 312 & 0.50 & 7.7 & 3.8 \\
\hline & 350 & 9.6 & 11.1 & 244 & 0.37 & 6.7 & 4.4 \\
\hline & 380 & 9.6 & 11.1 & 280 & 0.48 & 7.5 & 3.6 \\
\hline \multirow{3}{*}{$\mathrm{N}_{2}+\mathrm{O}_{2}$} & 300 & 9.8 & 11.3 & 320 & 0.53 & 7.7 & 3.6 \\
\hline & 350 & 9.6 & 11.1 & 262 & 0.37 & 8.0 & 3.1 \\
\hline & 380 & 9.5 & 11.0 & 87 & 0.15 & 7.8 & 3.2 \\
\hline
\end{tabular}


Table 2: \% of carbon originally present in the hybrid mesophase remaining in the $\mathrm{TiO}_{2}$ materials after crystallization

\begin{tabular}{ccc}
\hline Atmosphere & Temperature $\left({ }^{\circ} \mathrm{C}\right)$ & $\% \mathrm{C}$ \\
\hline $\mathrm{N}_{2}$ & 300 & 8.1 \\
& 350 & 8.3 \\
& 380 & 3.2 \\
\hline Synthetic air & 300 & 8.6 \\
& 350 & 14.5 \\
& 380 & 2.2 \\
\hline $\mathrm{N}_{2}+\mathrm{O}_{2}$ & 300 & 8.2 \\
& 350 & $<0.2$ \\
\hline
\end{tabular}


Table 3 : Structure, repetition distance $(d)$, cell parameter $\left(a_{0}\right)$, specific surface area $\left(S_{B E T}\right)$, total pore volume $\left(\mathrm{V}_{\mathrm{P}}\right)$, pore diameter $(\varnothing)$ and wall thickness $(\mathrm{e})$ of the material obtained after ethanol extraction as a function of both the pressure of ammonia and the duration of the treatment under this pressure

\begin{tabular}{|c|c|c|c|c|c|c|c|c|}
\hline $\begin{array}{l}\mathrm{P}_{\mathrm{NH} 3} \\
\text { (bar) }\end{array}$ & $\begin{array}{l}\text { Duration } \\
\text { (h) }\end{array}$ & Structure & $\mathrm{d}(\mathrm{nm})$ & $\mathrm{a}_{0}(\mathrm{~nm})$ & $\begin{array}{c}\mathrm{S}_{\mathrm{BET}} \\
\left(\mathrm{m}^{2} / \mathrm{g}\right)\end{array}$ & $\begin{array}{c}\mathrm{Vp} \\
\left(\mathrm{cm}^{3} / \mathrm{g}\right)\end{array}$ & $\varnothing(\mathrm{nm})$ & $\begin{array}{c}\mathrm{e} \\
(\mathrm{nm})\end{array}$ \\
\hline \multirow{6}{*}{0.5} & 3 & Hexa & 11.7 & 13.6 & 410 & 0.42 & 9.8 & 3.8 \\
\hline & 6 & Hexa & 11.6 & 13.4 & 400 & 0.42 & 9.5 & 3.9 \\
\hline & 9 & Hexa & 11.4 & 13.1 & 425 & 0.55 & 9.6 & 3.5 \\
\hline & 12 & Hexa & 11.9 & 13.7 & 365 & 0.65 & 9.8 & 3.9 \\
\hline & 18 & Hexa & 12.0 & 13.9 & 392 & 0.66 & 10.4 & 3.5 \\
\hline & 24 & Hexa & 12.5 & 14.4 & 360 & 0.62 & 10.4 & 4.0 \\
\hline \multirow{6}{*}{1} & 3 & Hexa & 11.0 & 12.7 & 312 & 0.48 & 8.4 & 4.3 \\
\hline & 6 & Hexa & 11.0 & 12.7 & 355 & 0.54 & 8.8 & 3.9 \\
\hline & 9 & Hexa & 10.7 & 12.4 & 377 & 0.57 & 8.5 & 3.9 \\
\hline & 12 & Hexa & 11.5 & 13.3 & 350 & 0.60 & $7.5-10.3$ & \\
\hline & 18 & Hexa & 11.2 & 12.9 & 423 & 0.75 & $7.5-10.2$ & \\
\hline & 24 & Hexa & 11.9 & 13.7 & 366 & 0.60 & 7.9-9.8 & \\
\hline \multirow{6}{*}{1.5} & 3 & Hexa & 11.4 & 13.2 & 305 & 0.52 & 9.2 & 4.0 \\
\hline & 6 & Hexa & 11.3 & 13.0 & 335 & 0.45 & 9.0 & 4.0 \\
\hline & 9 & Hexa & 11.1 & 12.8 & 380 & 0.56 & $8.5-9.9$ & \\
\hline & 12 & Hexa & 12.4 & 14.3 & 355 & 0.66 & $8.2-10.0$ & \\
\hline & 18 & Hexa & 12.1 & 14.0 & 322 & 0.65 & $8.6-9.8$ & \\
\hline & 24 & Hexa & 11.9 & 13.7 & 340 & 0.60 & 8.3-9.9 & \\
\hline \multirow{6}{*}{2} & 3 & Hexa & 11.2 & 12.9 & 374 & 0.68 & $8.2-9.9$ & \\
\hline & 6 & Hexa & 10.0 & 11.5 & 390 & 0.68 & $7.7-9.4$ & \\
\hline & 9 & Wormhole & 10.0 & & 423 & 0.75 & $7.7-9.1$ & \\
\hline & 12 & Wormhole & 10.5 & & 325 & 0.47 & $6.2-9.4$ & \\
\hline & 18 & Wormhole & 11.4 & & 346 & 0.60 & $6.5-10$ & \\
\hline & 24 & Wormhole & 11.4 & & 375 & 0.65 & $6.7-9.8$ & \\
\hline \multirow{6}{*}{2.5} & 3 & Hexa & 10.2 & 11.8 & 415 & 0.70 & $7.5-9.6$ & \\
\hline & 6 & Hexa & 10.1 & 11.7 & 410 & 0.70 & $7.7-9.4$ & \\
\hline & 9 & Wormhole & 10.5 & & 378 & 0.65 & 7.6-9.7 & \\
\hline & 12 & Wormhole & 12.1 & & 380 & 0.65 & $6.8-9.8$ & \\
\hline & 18 & Wormhole & 11.9 & & 370 & 0.57 & $6.8-10.1$ & \\
\hline & 24 & Wormhole & 12.7 & & 395 & 0.65 & $6.7-9.4$ & \\
\hline \multirow{6}{*}{3} & 3 & Hexa & 11.7 & 13.5 & 345 & 0.60 & $8.8-10.0$ & \\
\hline & 6 & Wormhole & 10.2 & & 390 & 0.67 & $7.0-9.0$ & \\
\hline & 9 & Wormhole & 10.4 & & 375 & 0.65 & 7.0-9.6 & \\
\hline & 12 & Wormhole & 10.8 & & 407 & 0.62 & $7.5-9.7$ & \\
\hline & 18 & Wormhole & 11.7 & & 413 & 0.63 & $7.2-10.0$ & \\
\hline & 24 & Wormhole & 11.4 & & 360 & 0.55 & $7.5-10.0$ & \\
\hline
\end{tabular}


Table $4: \%$ of $\mathrm{N}$ and $\%$ of $\mathrm{C}$ present in the hybrid mesophase and in the $\mathrm{TiO}_{2}$ materials after solvent extraction and calcination at $380^{\circ} \mathrm{C}$ under synthetic air

\begin{tabular}{ccccc}
\hline & \multicolumn{2}{c}{ Hybrid mesophase } & \multicolumn{2}{c}{ Calcined $\mathrm{TiO}_{2}$} \\
\hline $\mathrm{P} \mathrm{NH}_{3}$ (bar) & $\% \mathrm{~N}$ & $\% \mathrm{C}$ & $\% \mathrm{~N}$ & $\% \mathrm{C}$ \\
\hline 0.5 & 5.3 & 22.8 & 1.6 & 1.6 \\
1.0 & 5.2 & 22.9 & 1.5 & 1.4 \\
1.5 & 5.5 & 24.6 & 1.7 & 1.5 \\
2.0 & 5.6 & 22.0 & 1.5 & 1.4 \\
2.5 & 6 & 21.0 & 1.6 & \\
\hline
\end{tabular}


Figure 1
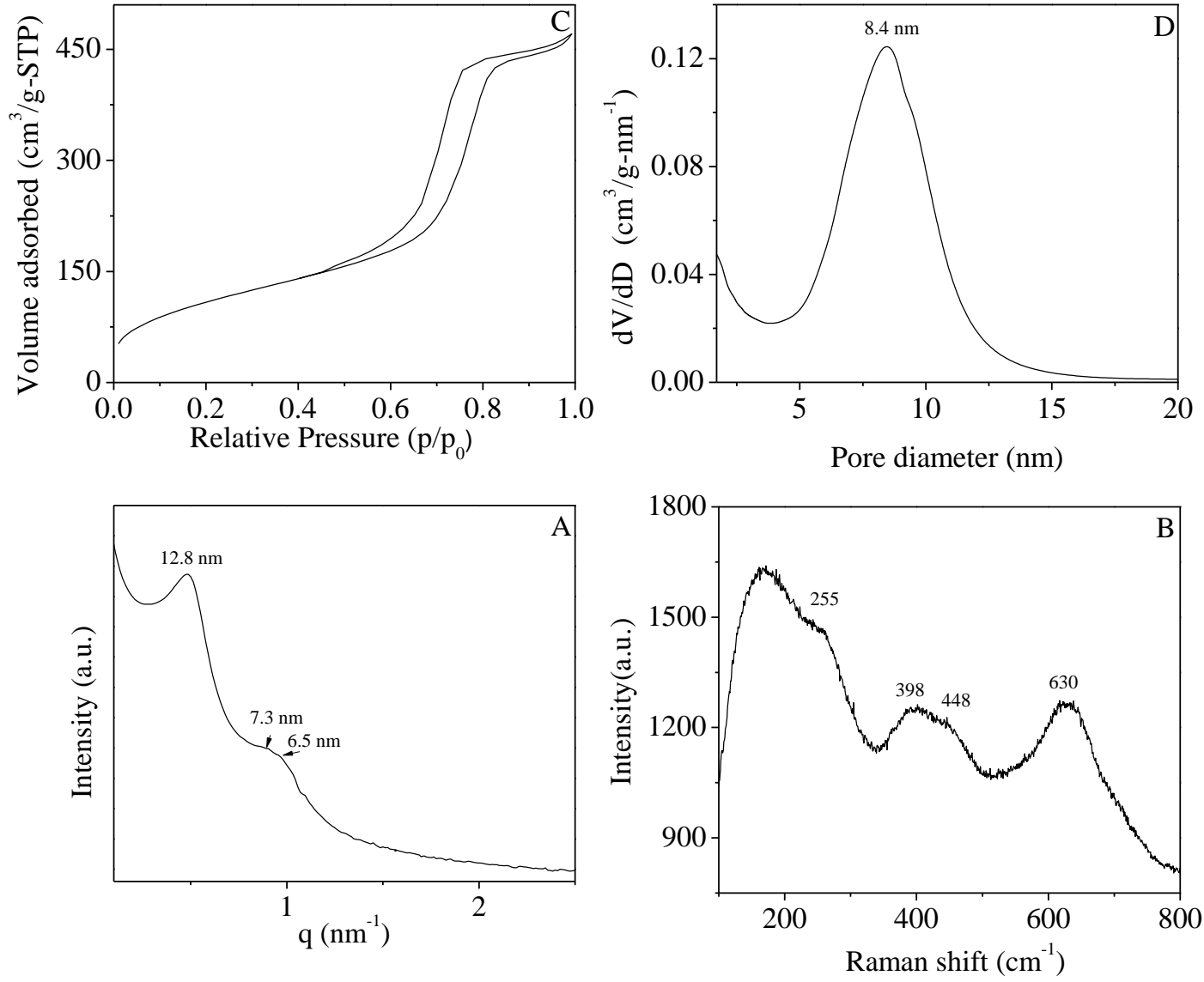
Figure 2

A

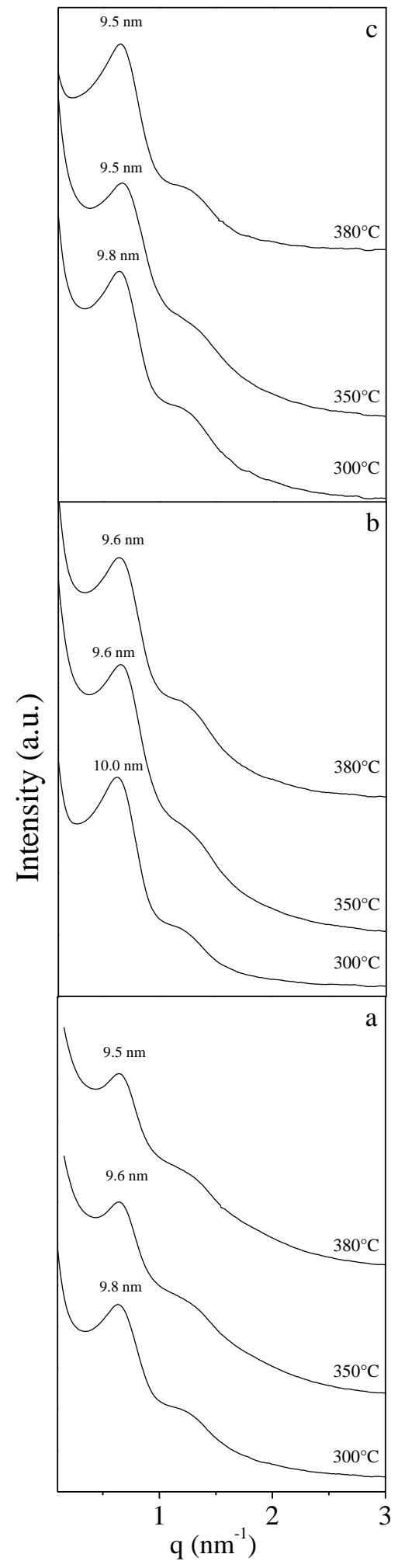

B

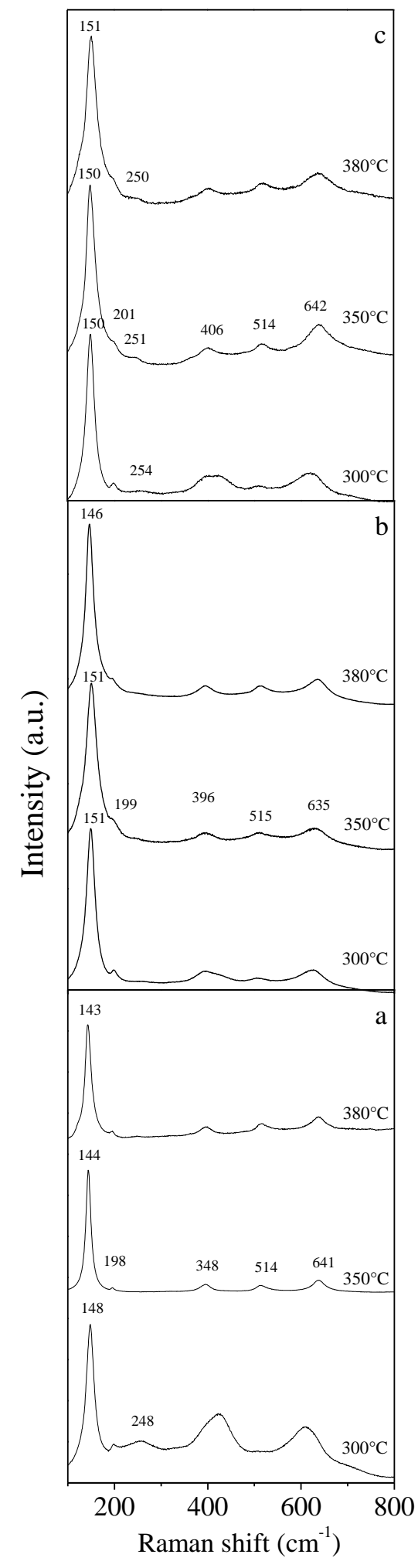


Figure 3

A

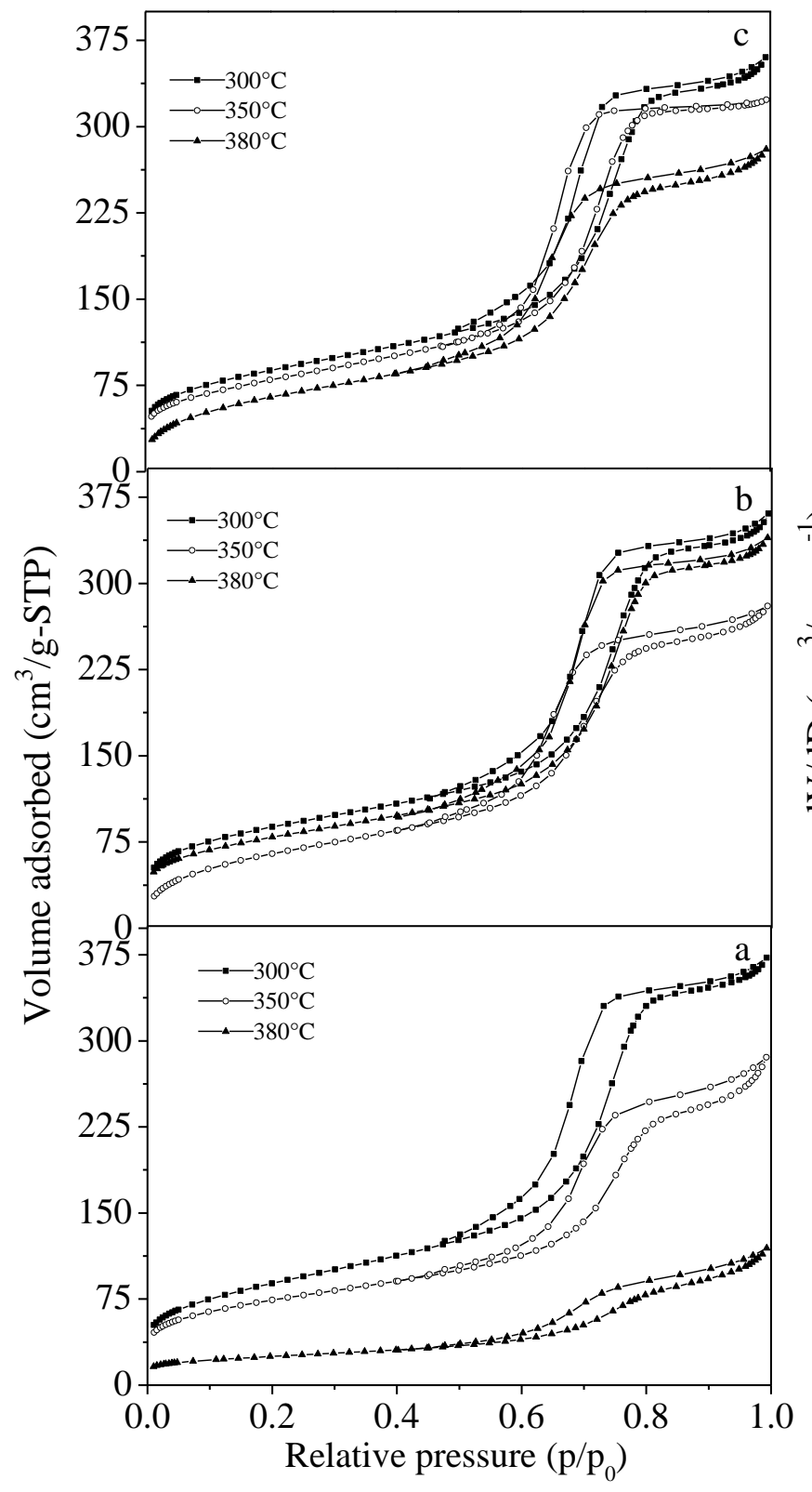

B

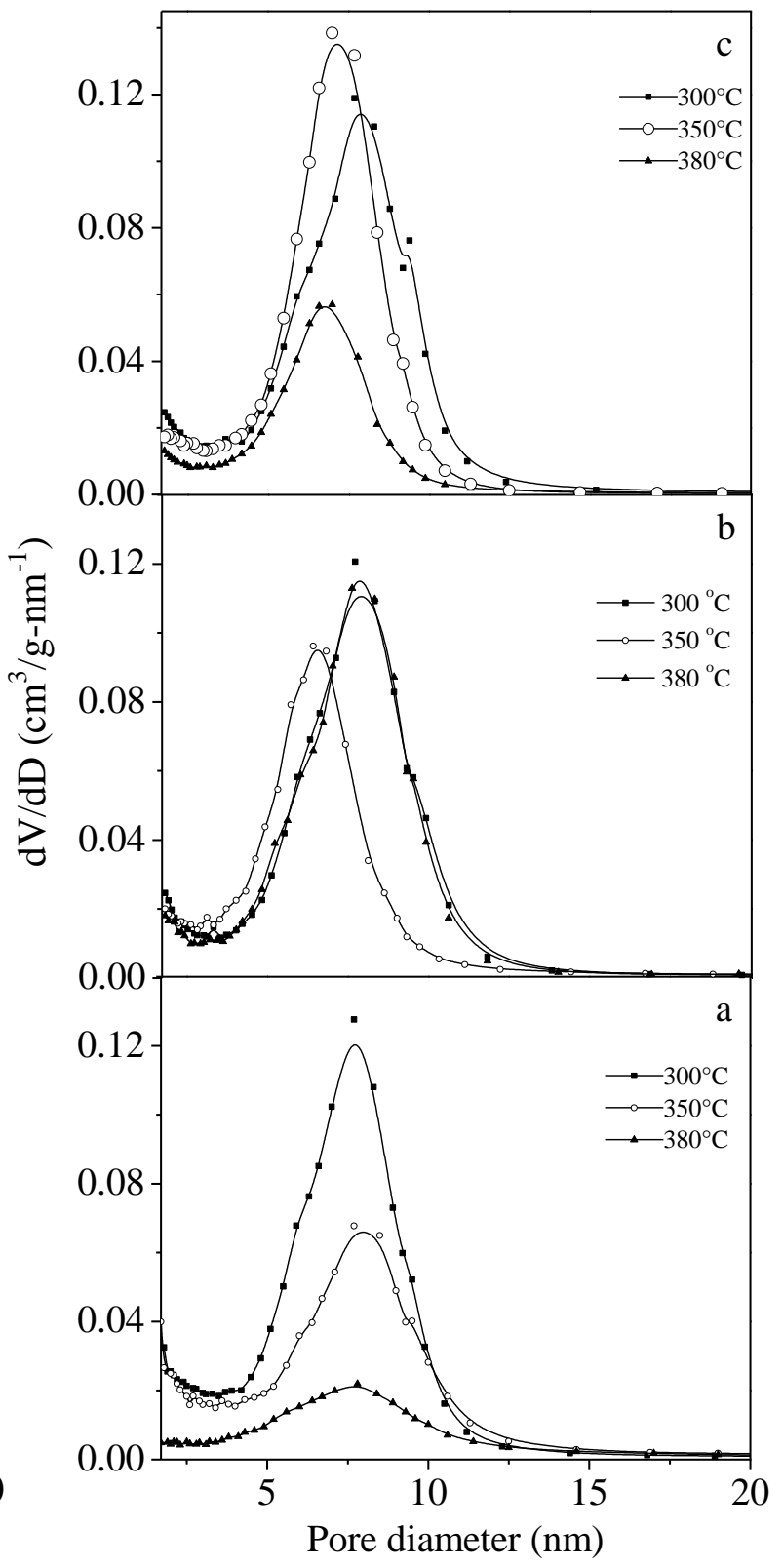


Figure 4
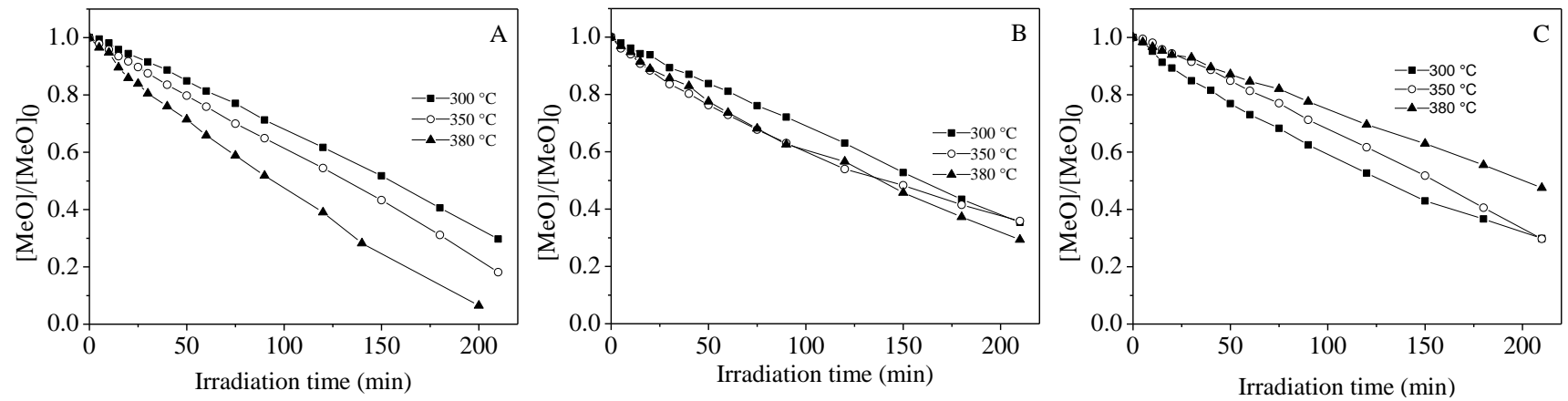
Figure 5
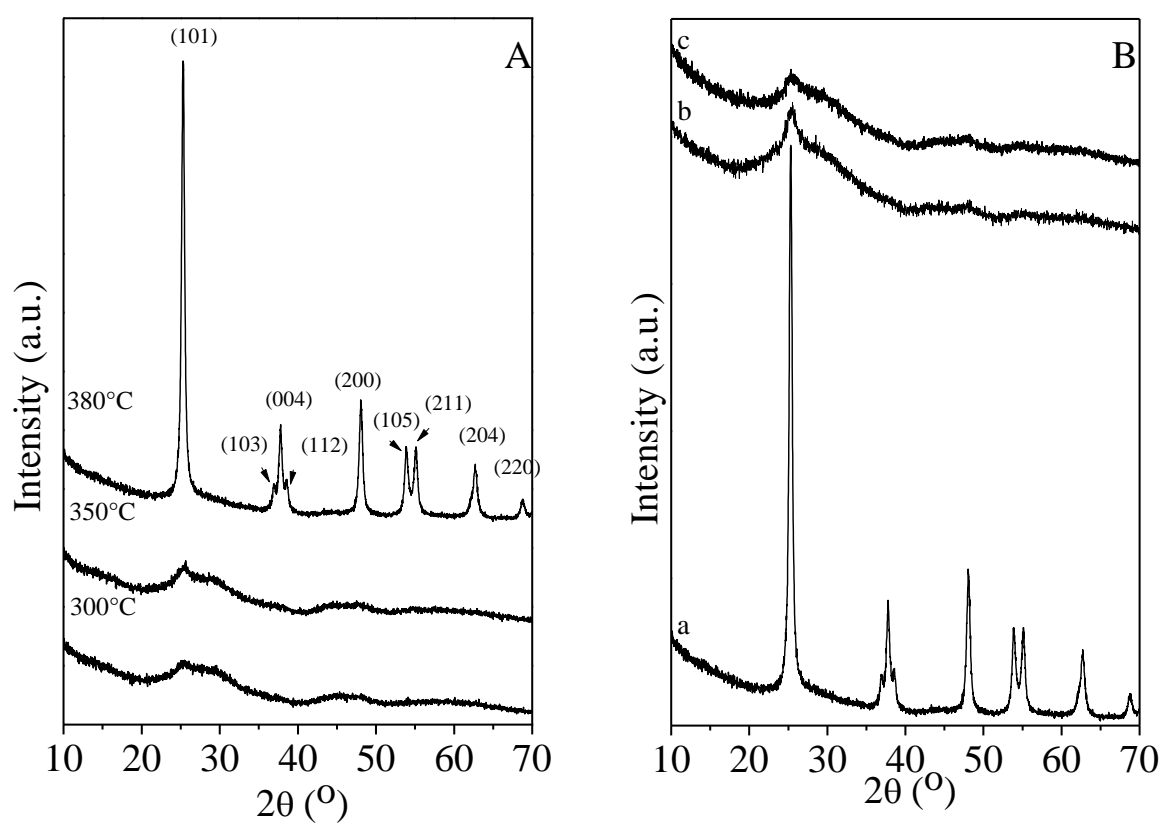
Figure 6
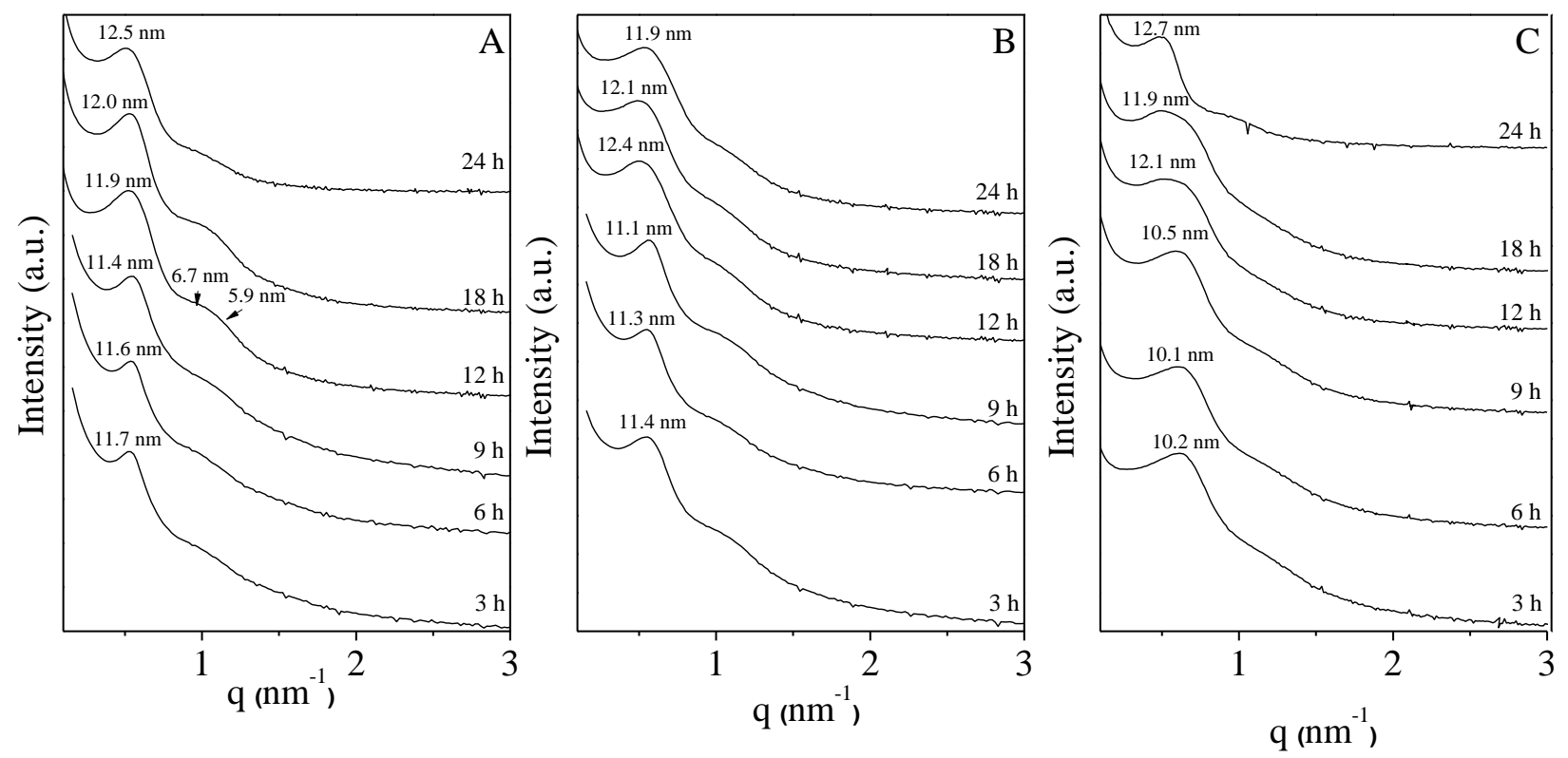
Figure 7

A

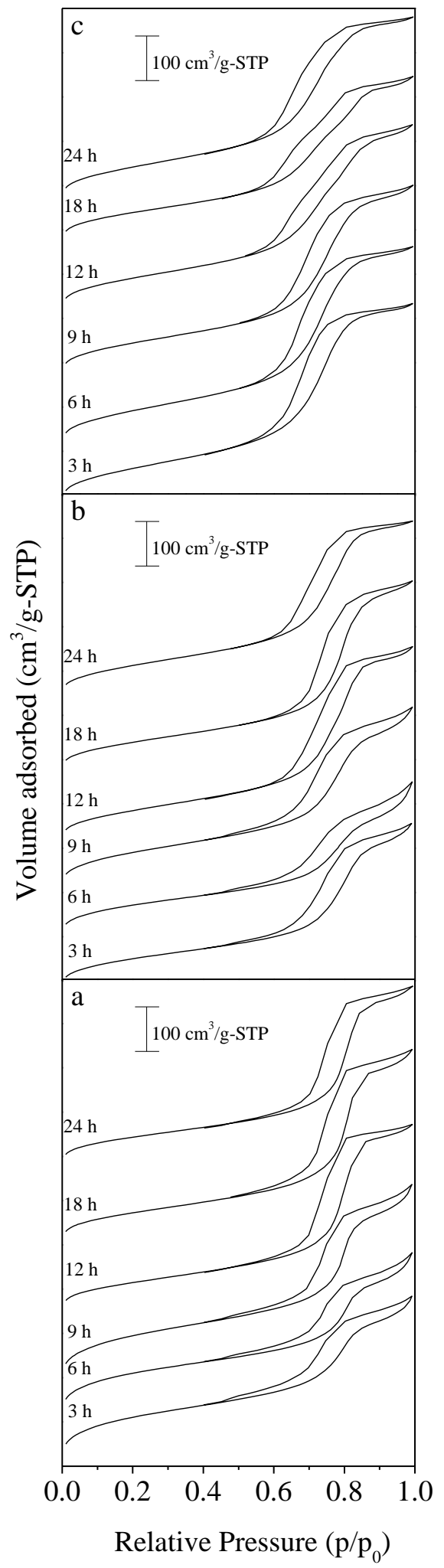

B

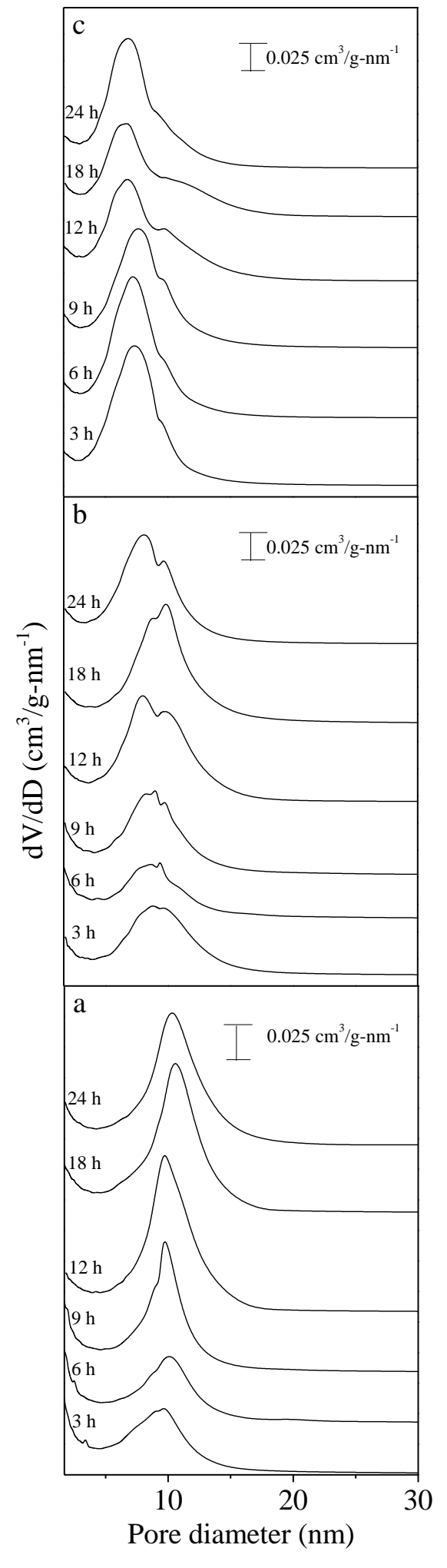


Figure 8

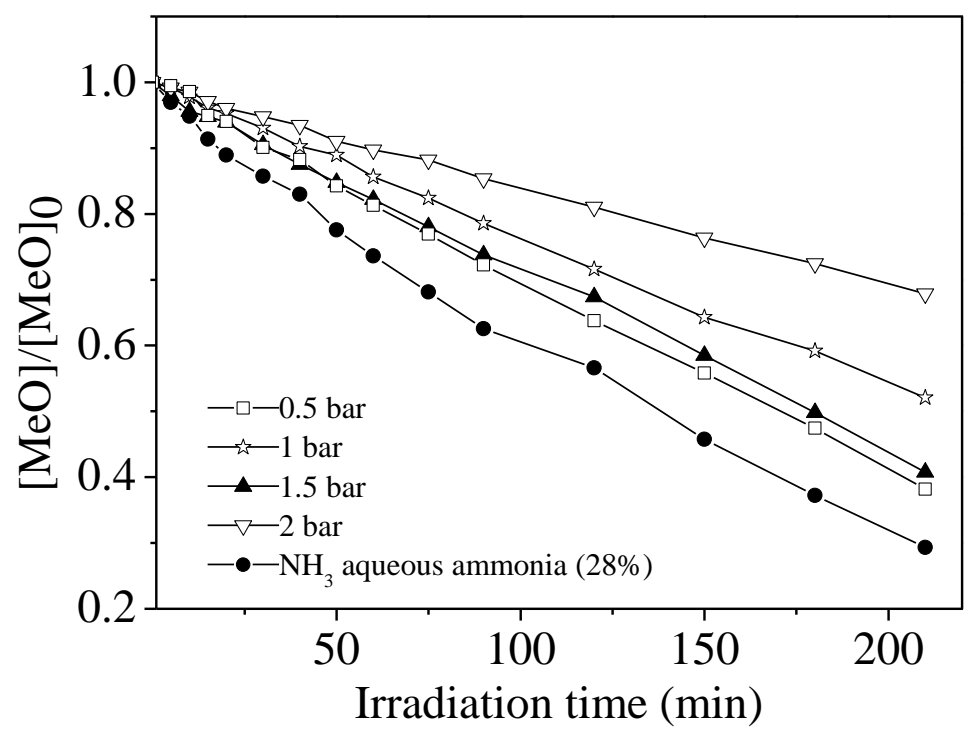


Figure 9
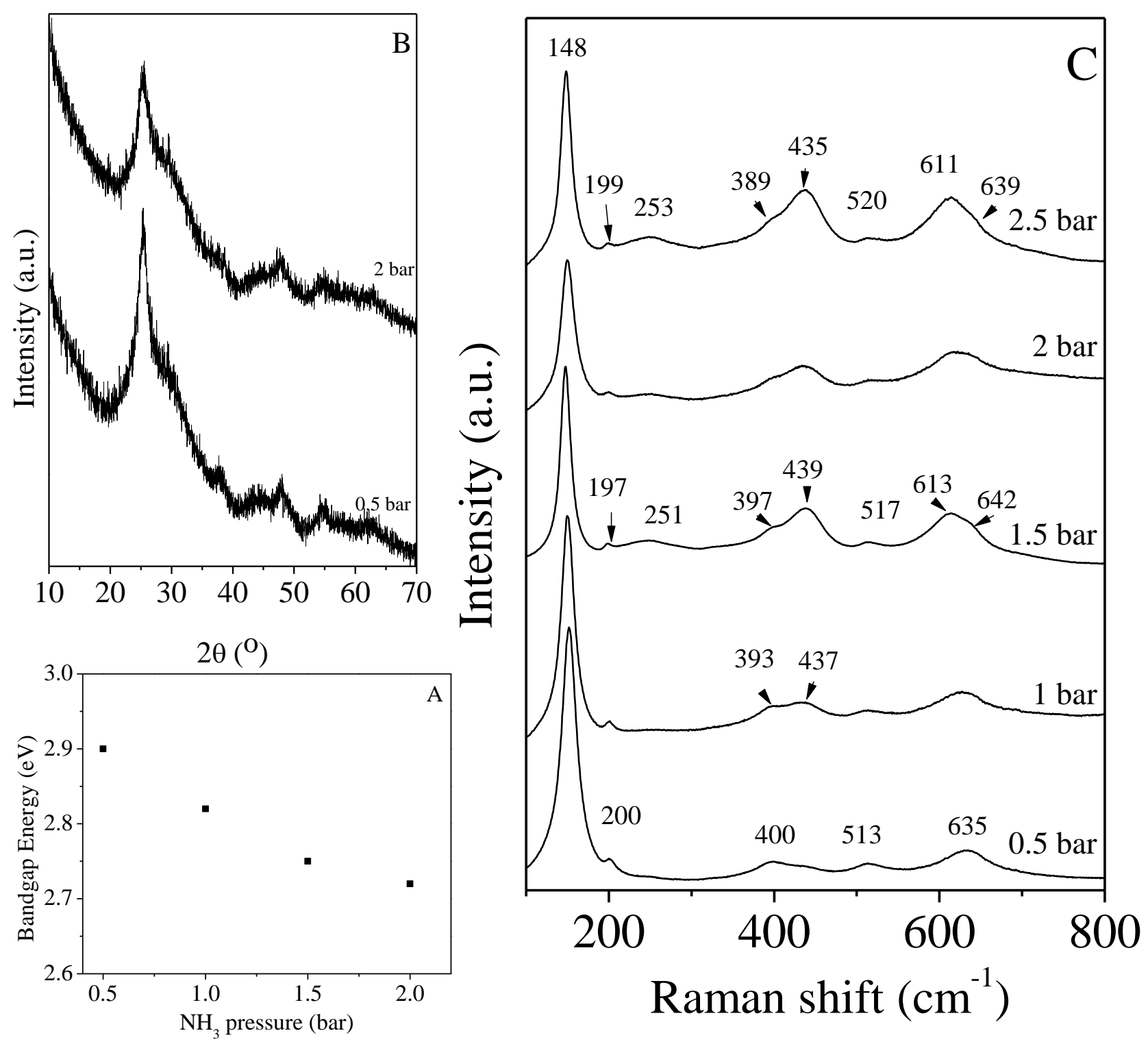